\title{
PANORAMA DO AgRONEGÓCIO NA AMÉRICA LATINA: UMA ANÁliSE EXPLORATÓRIA (2000-2015)
}

\author{
Alexander Bruno Pegorare ${ }^{1}$, Dany Rafael Fonseca Mendes², Tito Belchior Silva Moreira³, Michel \\ Constantino ${ }^{4}$
}

\begin{abstract}
RESUMO - No presente estudo, foi realizada uma pesquisa bibliográfica exploratória dos últimos quinze anos (2000-2015), com o objetivo de verificar o panorama do agronegócio nos principais países da América Latina, e discutir os principais trabalhos que relacionaram o agronegócio ao desempenho econômico e social, analisando, ainda, questões relativas ao meio ambiente e à segurança alimentar. As evidências empíricas dos diferentes trabalhos mostraram que, no período selecionado, houve desenvolvimento econômico e social nos países latino-americanos, sem, necessariamente, ter havido suporte no agronegócio para todos os países que compõem a amostra selecionada para este trabalho. Com relação ao meio ambiente e à segurança alimentar, é possível concluir que, entre 2000 e 2015, houve uma lenta evolução nas políticas nacionais nos países latino-americanos.
\end{abstract}

Palavras chave: agronegócio, américa latina, desenvolvimento socioeconômico, meio ambiente, segurança alimentar.

\section{AGRIBUSINESS IN LATIN AMERICA: AN EXPLORATORY ANALYSIS (2000- 2015)}

\begin{abstract}
In the present study, an exploratory bibliographical research of the last fifteen years (20002015) was carried out, in order to verify the agribusiness landscape in the main Latin American countries, and to discuss the main works that related agribusiness to economic and social performance, Examining issues related to the environment and food safety. The empirical evidence from the different studies showed that in the selected period there was economic and social development in the Latin American countries, without necessarily having been supported in agribusiness for all the countries that make up the sample selected for this work. With regard to the environment and food security, it is possible to conclude that between 2000 and 2015, there was a slow evolution in national policies in the Latin American countries.
\end{abstract}

Keywords: agribusiness, environment, food security, Latin America, socioeconomic development.

\footnotetext{
${ }^{1}$ Doutorando do Programa de Ciências Ambientais e Sustentabilidade Agropecuária, da Universidade Católica Dom Bosco - UCDB, Campo Grande/MS. E-mail: alexander.pegorare@ibge.gov.br

${ }^{2}$ Pesquisador e orientador do Programa Agentes Locais de Inovação (ALI), do Serviço Brasileiro de Apoio às Micro e Pequenas Empresas - Sebrae, Brasília/DF. E-mail: rafael.dany@gmail.com

${ }^{3}$ Programa de Pós-Graduação em Economia, da Universidade Católica de Brasília - UCB, Brasília/DF. E-mail: tito@ucb.br

${ }^{4}$ Programa de Pós-Graduação em Ciências Ambientais e Sustentabilidade Agropecuária, da Universidade Católica Dom Bosco - UCDB, Campo Grande, MS. E-mail: michel@ucdb.br
} 


\section{INTRODUÇÃO}

A contribuição da agropecuária para o crescimento econômico e social na América Latina tem sido um assunto de considerável debate entre os pesquisadores. Inicialmente, da década de 1950 até o final do século passado, abordava-se apenas o papel do agronegócio na promoção do desenvolvimento econômico nos países latino-americanos, sem questionamento de outros temas, em uma população ainda marcada pela baixa renda e fragmentada politicamente, após longos períodos de domínio colonial (América, 1950; Stein \& Stein, 1970; Chenery \& Eckstein, 1970; Spraos, 1980; Gregório, 1992). Grande parte daquelas investigações era de natureza qualitativa e enfatizava um potencial impacto das ligações inter setoriais entre produção agrícola e industrial. Após um período de calmaria nas publicações sobre este assunto, uma recente enxurrada de estudos teóricos e empíricos sobre o tema sugere que, nos últimos anos, o debate tem aumentado, não somente no campo econômico, mas agora levando em conta as questões sociais, ambientais e de segurança alimentar (Silva et al., 2012; Rocha de Souza, 2013; Massardier \& Sabourin, 2013; Beleño, 2014; Perrotti, 2015; Martinezhyphenvazquez \& Vulovic, 2014; Tello, 2015). Pesquisas neste sentido são cruciais porque auxiliam nas decisões políticas nacionais e internacionais, permitindo verificar como os recursos para os setores do agronegócio e de infraestrutura têm sido aplicados em favor do desenvolvimento econômico e social de seus países.

Os resultados das publicações estudadas do século passado relacionadas ao fomento do agronegócio e à economia local/regional não apresentam unanimidade entre os pesquisadores. Enquanto alguns afirmavam que o desenvolvimento do agronegócio é uma condição prévia para a industrialização e o crescimento econômico, outros discordavam fortemente, argumentando noutra direção. Nesse sentido, vários autores afirmaram que o crescimento da economia geral depende do desenvolvimento do setor agropecuário (Schultz, 1964; Gollin et al., 2002). Os defensores do desenvolvimento econômico alavancado pela agropecuária se baseavam no argumento de que o investimento na agricultura e na criação de infraestruturas de suporte à cadeia produtiva, com instituições de apoio, seria um prérequisito para o crescimento econômico nacional. Aqueles pesquisadores observaram que, por meio do seu efeito sobre a renda rural e por fornecer recursos para a transformação da economia industrializada, o crescimento do setor primário poderia ser um catalisador para o crescimento da produção nacional. Bhagwati e Srinivasan
(1975) ratificaram este argumento, ressaltando que tentativas anteriores das nações em desenvolvimento de industrializar sua economia sem o incremento prévio do setor agrícola resultaram em taxas de crescimento econômico e distribuição de renda enviesadas.

Por outro lado, entre os anos 1930 e 1970, os países latino-americanos cresceram em ritmo extraordinário (Bresser-Pereira, 2012). Naquele período, a América Latina iniciou um processo de substituição de importações industriais, evidenciados pelas profundas mudanças no sistema internacional, como a revolução tecnológica e a internacionalização da economia mundial, abrindo novos caminhos para a economia regional. As estratégias nacionais de desenvolvimento implicavam na proteção da indústria nascente nacional (ou industrialização por substituição de importações) e, ainda, na promoção de poupança forçada pelo Estado. A abertura comercial, a liberalização financeira e as privatizações mudaram radicalmente as regras do jogo segundo as quais operavam empresários e trabalhadores nos países latino-americanos (Diniz, 1992; Stallings \& Peres Nunez, 2002). Prebisch (1949) constatou que, já naquela época, o aproveitamento industrial de mão de obra ociosa no campo já significava uma melhora da economia regional, traduzindo-se em aumento líquido da renda nacional dos países que estavam se industrializando.

Já no século atual, a forte globalização e a formação de grandes blocos comerciais originaram novos atores, além de novos investimentos estrangeiros no mercado interno latino-americano, aumentando, assim, a importância deste mercado para a economia mundial. Observa-se, contudo, que estudos empíricos recentes produziram evidências conflitantes e continua a haver uma falta de consenso sobre o efeito do agronegócio no crescimento econômico e desenvolvimento social. Por meio de uma revisão bibliográfica exploratória, o presente estudo, tem por objetivo selecionar publicações dos principais países latino-americanos, realizados nos últimos quinze anos, na forma de artigos científicos, dados estatísticos de instituições oficiais, dissertações e teses, para expor os consensos, as divergências, e possíveis lacunas que ainda possam ser exploradas com relação ao tema. Alguns dos trabalhos selecionados discutiram, de forma agregada, todos os países latino-americanos, enquanto outras pesquisas tiveram o objetivo específico de estudar apenas um ou um bloco de países. Também foram divulgados trabalhos que abordaram as relações comerciais dos países da América Latina com os seus principais parceiros comerciais, conforme Figura 1. 


\begin{tabular}{|c|c|}
\hline Autor, fonte, ano & Locais pesquisados \\
\hline $\begin{array}{l}\text { Cepalstat, banco de dados, 2016; Faostat, banco de dados, 2016; Landini, F., } \\
\text { artigo, 2016; Tello, M.D., artigo, 2015; Vakis, et al., resumo, 2015; Beleño, } \\
\text { C.A.M., artigo, 2014; Martinezhyphenvazquez \& Vulovic, artigo, 2014; } \\
\text { Mascia et al., artigo, 2014; Massardier \& Sabourin, artigo, 2013; Rocha de } \\
\text { Sousa, M., resumo, 2013; Svampa, M., artigo, 2013; Wilkinson, J., artigo, } \\
\text { 2013; Montaldo et al., artigo, 2012; Silva et al., artigo, 2012; Moltoni \& } \\
\text { Gorenstein, artigo, 2010; Cochrane, M.A., Livro, 2009; Colburn, F., } \\
\text { dissertação, 2009; Teubal, M., artigo, 2008; Gollin et al., artigo, 2002. }\end{array}$ & \\
\hline \multicolumn{2}{|l|}{$\begin{array}{c}\text { Única, nota, 2016; Almeida et al., artigo, 2014; Da Silva, L.G., artigo, 2014; } \\
\text { Richards et al., artigo, 2014; Santos et al., artigo, 2014; Pinheiro, A., tese, } \\
\text { 2011; Bragato et al., artigo, 2008; Campos \& Campos, artigo, 2007; Garrett } \\
\text { et al., artigo, } 2002 .\end{array}$} \\
\hline $\begin{array}{l}\text { Sacchi \& Gasparri, artigo, 2015; Reboratti, C., artigo, 2010; Krapovickas, J., } \\
\text { tese, } 2009 .\end{array}$ & \\
\hline \multicolumn{2}{|l|}{ Rehner, et al., artigo, 2014; Castillo-Vergara, M., artigo, 2013.} \\
\hline \multicolumn{2}{|l|}{ Maletta \& Gómez, artigo, 2015.} \\
\hline \multicolumn{2}{|l|}{ Sanz et al., artigo, 2012.} \\
\hline Valdez-Vazquez et al., artigo, 2008. & \\
\hline
\end{tabular}

\begin{tabular}{l} 
Aoki, M., artigo, 2013. \\
Perrotti, D., artigo, 2015; Rosa et al., artigo, 2006. \\
Lorenzo \& Yamin Vazquez, artigo, 2016. \\
\hline Huacuja, F. E., artigo, 2013. \\
\hline O'Connor, E., artigo, 2013. \\
Beghin, John C., artigo, 2015.
\end{tabular}

Figura 1 - Resultado do estudo quali-quantitativo, de nível exploratório-descritivo, com base nos trabalhos dos últimos quinze anos, por meio de estratégias bibliográficas e documentais, segundo os locais de interesse pesquisados. 
De forma não exaustiva, os trabalhos selecionados foram considerados importantes para a pesquisa exploratória, por tratar de temas que agregam valor ao debate sobre o agronegócio e desenvolvimento socioeconômico, além de tratar de temas considerados importantes para o artigo, como meio ambiente e segurança alimentar.

\section{Panorama do agronegócio nos países da América Latina}

Primeiramente é necessário separar os produtores rurais em dois grandes grupos: grandes e médios produtores, caracterizados em sua maioria pela baixa diversificação de produção e alta especialização (focados principalmente em commodities tradicionais); e pequenos produtores, os quais, normalmente, têm sua mão de obra formada na esfera familiar, com alto grau de diversificação e baixo grau de especialização. Como exceção à regra, na Colômbia, Guatemala, Equador e México, também há alguns pequenos produtores de commodities agrícolas tradicionais, como café, cacau, banana e laranja (Wilkinson, 2003). Com relação aos pequenos produtores, a solução dominante de desenvolvimento para este grupo, nos últimos anos foi: a utilização de programas governamentais de subsídio à produção; a compra de produtos; a formação de associações e cooperativas para competir em escala com grandes produtores, diminuindo os custos para alcançar mercados que necessitem fornecimento programado; a agregação de valor aos produtos, através da agro industrialização e obtenção de selos, certificados e práticas produtivas baseadas em critérios ambientais, sociais, e de saúde (ex.: agroecológicos e orgânicos). Assim, segundo Wilkinson (2003), os avanços na América Latina para os pequenos produtores, que alcançaram a demanda das redes varejistas, já que as grandes redes de supermercados investiram em novos consumidores na última década, com uma crescente presença nos bairros mais pobres das metrópoles, bem como no interior dos países e também em países menores, como Costa Rica, Honduras e Nicarágua, necessitando de uma regionalização dos seus canais de suprimento, apesar destes setores estarem focalizados fundamentalmente no segmento de frutas, legumes e verduras.

Mesmo com o aumento do fornecimento de alimentos por pequenos produtores, Landini (2016) cita quinze principais desafios que os agricultores sitiantes necessitam ainda superar na América Latina, aqui sintetizados em quatro: (1) práticas produtivas inapropriadas e falta de adoção de novas tecnologias, ocasionadas principalmente pela baixa formação educacional do produtor; (2) passividade e/ou falta de participação dos produtores nos distintos projetos e iniciativas, já que, não raramente, o pequeno agricultor se coloca em uma situação de clientelismo para se organizar, obter assistência técnica/custeio e vender seus produtos; (3) instabilidade e fragilidade da situação laboral do pequeno produtor, o qual, muitas vezes, cultiva para subsistência e fica refém de trabalhos temporários, frequentemente análogos à escravidão; (4) falta de políticas locais apropriadas ao desenvolvimento e extensão rural.

O outro grande grupo são os médios e grandes produtores rurais, produtores de commodities tradicionais, talvez os grandes beneficiados pelo agronegócio nos últimos anos. Segundo Teubal (2008), a América Latina, implantou um modelo globalizado, com predomínio de capital financeiro, que se orienta no sentido da especialização crescente em determinadas commodities voltadas para o mercado externo, com uma tendência à concentração em grandes unidades de exploração. Nesse sentido, tornaram-se hegemônicos, a partir da década de 1970 , os programas de ajuste estrutural impulsionados pelo Fundo Monetário Internacional (FMI) e pelo Banco Mundial aplicados nos países latino-americanos. As privatizações, isenções de todo tipo e abertura à economia mundial, assim como a ortodoxia fiscal, transformaram-se em aspectos centrais das políticas econômicas, apoiadas no endividamento externo e na primazia dos interesses do capital financeiro. Essas mudanças no panorama da política econômica incidiram significativamente sobre os respectivos setores agrários de cada país (Massardier, 2013). A partir de então, naquela nova fase de desenvolvimento do capitalismo, empresas multinacionais conseguem controlar segmentos importantes dos sistemas agro alimentícios, tais como: a indústria alimentícia, a indústria de sementes, a produção de agroquímicos e outros insumos que são vendidos massivamente aos produtores agropecuários. Logo, a possibilidade de fazer contratos casuais para uma safra permitiu aos grandes proprietários obterem a assistência de multinacionais para plantar cereais e oleaginosas e, por conseguinte, atingir determinadas rendas que, de outro modo, não teriam como obter (Beleno, 2014).

No setor produtivo e econômico da pecuária, a bovinocultura de corte se consolidou no Brasil e na 
Argentina, principalmente pelos seguintes fatores: a) aumento do poder aquisitivo no mercado interno; b) menor custo de produção da pecuária extensiva, comparada ao confinamento dos Estados Unidos e da União Europeia; c) demanda crescente de países populosos por proteína, como a China; e d) preferência do consumidor mundial pelo boi criado no pasto após o advento da doença da "vaca louca" (Da Silva, 2014). Assim, a América Latina passou a construir um novo cenário para o agronegócio. Na pecuária, em 2002, o Brasil superou a Índia e passou a possuir o maior rebanho bovino mundial, evoluindo para uma marca acima de 210 milhões de cabeças em 2013 (FAOSTAT, s.d.). A Argentina também ocupou um lugar de destaque, com rebanho acima de 50 milhões de cabeças em 2013 (FAOSTAT, s.d.).

Com o aumento da produção de soja no continente, criou-se um ambiente propício para a produção de rações proteicas, e, com isso, houve um aumento na produção de aves, suínos e peixes. Logo, o Brasil obteve um papel relevante na produção global de aves e suínos, pois, em 2013, foi o quarto maior produtor mundial de aves (1.248.786 unidades produzidas) e o terceiro maior produtor mundial de suínos (36.743.593 unidades produzidas) (FAOSTAT, s.d.).

AArgentina se tornou um dos maiores exportadores de soja mundial, com quase $95 \%$ do total da safra nacional vendidos no mercado mundial. No período de 2001 a 2010 , entre $15 \%$ e $27 \%$ dos grãos de soja produzidos na Argentina foram exportados diretamente em grão, e $70 \%$ foi processado industrialmente no país, voltado para exportação aos países vizinhos e para consumo interno (Silva et al., 2012).

O agronegócio no Chile também se desenvolveu muito nos últimos anos, e o país passou a ser um grande exportador de salmão de cativeiro, conhecido como salmão do atlântico (Salmo salar). Segundo a Comissão Nacional de Investigação Científica e Tecnologia do Chile, no ano de 2012, a produção aquícola do país alcançou um volume de 6,07 milhões de toneladas entre produção industrial e artesanal, sendo o produto com maior importância econômica na balança comercial chilena (Almeida, 2014). O forte dinamismo agro-produtivo no Chile foi observado também nas regiões localizadas na zona central daquele país, viabilizada principalmente pela irrigação, com predomínio de produção de uvas (frescas e processadas), sendo grande parte da produção destinada ao mercado externo (Castillo-Vergara, 2013).

$\mathrm{Na}$ atualidade a Colômbia é o terceiro maior exportador mundial de café, atrás apenas de Brasil e Vietnam (FAOSTAT, s.d.). Todavia, em cafés suaves (café arábica), a Colômbia é o primeiro colocado, enquanto o Brasil é um grande produtor de café tipo robusta ou canéfora, considerado inferior no comércio internacional.

O México é o quinto maior produtor mundial de ovos, além de ser o quarto maior produtor de aves poedeiras, tendo, por sua localização geográfica, se tornado um forte parceiro comercial e fornecedor de ração/produtos alimentícios industrializados para os Estados Unidos da América, por meio do Tratado NorteAmericano de Livre Comércio-NAFTA (Huacuja, 2013). Estima-se, ainda, que, no México, haja mais de 500.000 hectares, formados principalmente na região noroeste, produzindo frutas e hortaliças destinadas ao mercado externo (SILVA et al., 2012). Aquele país também se tornou o quarto maior produtor mundial de ração animal, e, assim, $61 \%$ dos três principais grãos utilizados para fabricação de ração (milho, sorgo e soja) são provenientes do mercado americano, sendo que o restante vem de sua produção nacional e de outros países (Huacuja, 2013).

Na Nicarágua, há um setor emergente nas regiões do Atlântico Sul e Central, especializadas na exportação de produtos lácteos vinculados a investimentos estrangeiros. Também se constatou o dinamismo na produção de gergelim, por parte de pequenos produtores, destinada a um nicho de mercado (chamado de "comercio justo", com produção orgânica) nas planícies do Pacífico e no trópico seco do ocidente da Nicarágua (Silva et al., 2012).

E, finalmente, no Peru, observou-se um crescimento do agronegócio centrado fundamentalmente na região costeira, onde médios e grandes produtores plantam hortaliças e frutas, todas destinadas ao mercado externo (Silva et al., 2012).

\section{DESENVOLVIMENTO ECONÔMICO E SOCIAL}

\subsection{Exportações de commodities agrícolas}

AAmérica Latina sofreu recentemente uma mudança pragmática, a partir da aplicação de algumas regras fundamentadas no consenso de Washington, como 
disciplina fiscal, abertura comercial, privatização das estatais, desregulamentação (afrouxamento de leis econômicas e trabalhistas) e possibilidade de investimento estrangeiro direto sem restrições. Essas alterações, segundo Svampa (2013), acarretaram uma exportação em grande escala de matérias-primas, como hidrocarbonetos (gás e petróleo), metais e minerais (cobre, ouro, prata, estanho, bauxita, zinco, etc.), produtos agrícolas (milho, soja e trigo), e biocombustíveis. Assim, a partir desta nova ordem, tanto econômica como políticoideológica, apoiada no boom dos preços internacionais das matérias-primas e da crescente demanda por bens de consumo pelos países tradicionais e potências emergentes dos últimos quinze anos, há vantagens comparativas visíveis para o crescimento econômico e para o aumento das reservas monetárias dos países latino-americanos (Svampa, 2013).

Os lucros provenientes da agropecuária desempenharam um papel vital nas interações entre os setores rurais e os urbanos, fomentando serviços e insumos agrícolas a partir dos centros urbanos locais, promovendo a diversificação das atividades e incentivando a criação de empregos não agrícolas (Garrett \& Chowdhury, 2004; Richards et al., 2014).

A China tem sido uma importante parceira comercial dos países sul-americanos, principalmente em função de seu crescimento econômico elevado, evidenciado a partir da década de 2000 até recentemente (OConnor, 2013). A partir do fortalecimento econômico chinês, país que conta com a maior população do mundo, houve uma necessidade cada vez maior de alimentos para suprir a demanda nacional chinesa (Aoki, 2013). A importância do comércio agrícola latino-americano com a China não é, de fato, a mesma para todos os países. Em particular, considerando os dezessete países da América Latina, algumas tendências comerciais podem ser apreciadas apenas entre alguns grupos de países. Nesse sentido, segundo OConnor (2013), os países do MERCOSUL (Mercado Comum do Sul) se beneficiaram pela expansão do comércio com a China, com a exportação intensiva de bens de segurança alimentar, como: grãos, óleos, carnes frescas e carnes processadas, além de produtos lácteos. Porém, os grandes destaques entre os principais produtos comercializados foram os da cadeia da soja, como o grão, o farelo e o óleo, produzidos, principalmente, pelo Brasil, pela Argentina, e, em menor grau, por Paraguai, Uruguai e Bolívia (OConnor, 2013).
Com relação ao NAFTA, o grupo tem integrado com sucesso as economias do México, dos Estados Unidos e do Canadá. No que diz respeito à agropecuária, o México exporta, notadamente para os Estados Unidos da América, frutas e vegetais, café, gado vivo e produtos têxteis. E, consequentemente, importa dos EUA grãos e outros alimentos, como soja e seus derivados, carne, algodão e têxteis (Beghin, 2015).

A produção de carne bovina na América Latina também é muito importante no cenário global, já que, em 2013, a região respondeu por 32\% da produção de gado de corte mundial. Os principais países produtores de carne naquele ano foram: o Brasil (51,6\% do total da produção de carne bovina da América Latina), Argentina (18,5\%), México $(9,4 \%)$, e Colômbia (5,1\%). Outros países que contribuíram acima $1 \%$ de toda a produção regional foram: Uruguai, Venezuela, Paraguai, Bolívia, Equador e Chile (FAOSTAT, s.d.). Os principais parceiros comerciais importadores de carne provenientes da América Latina, em 2013, foram: Rússia (18,2\%), Reino Unido (10,2\%), Egito (8,5\%) e EUA $(6,7 \%)$, segundo a FAOSTAT (2016).

Com relação à atividade canavieira na América Latina, Argentina, Brasil e México concentraram mais de dois terços do total produzido de cana de açúcar da região, entre 2000 e 2013 (FAOSTAT, s.d.). É importante ressaltar que, particularmente, a Argentina produz apenas açúcar para o consumo interno, enquanto México e Brasil produzem açúcar e etanol para o mercado interno e externo (Guedes et al., 2013). Brasil e Estados Unidos foram os maiores produtores mundiais de etanol, totalizando $70 \%$ da produção mundial entre 2003 e 2010. Embora perca por uma margem pequena para os Estados Unidos, o Brasil é o líder absoluto no ranking dos países que exportaram o produto - deteve cerca de $60 \%$ do mercado internacional de álcool. Os Estados Unidos, por sua vez, produziram o etanol a partir do milho, mas seu destino foi o mercado interno (Lorenzo \& Yamin Vazquez, 2016).

No Brasil, destacou-se o forte crescimento do agronegócio na região Centro-Oeste e, em menor medida, na região Sul, na qual três produtos se sobressaíram na última década: algodão, soja e frango, com altos investimentos, tendo em vista que os empresários utilizaram tecnologia de ponta e destinaram suas produções aos mercados externos (Silva et al., 2012). 
No caso da Guatemala, também se observou um crescimento importante na produção de hortaliças para a exportação em certas regiões da área central do país. Nas montanhas da Guatemala, destacou-se o aumento da produção de café para exportação (tipo "gourmet", diferente da "commodity"), cultivada por pequenos agricultores (Silva et al., 2012).

\subsection{Fatores benéficos relacionados ao desenvolvimento econômico e social}

Neste item, foram relacionados alguns trabalhos recentes, nos quais foram analisados fatores positivos relacionados ao desenvolvimento econômico e social, baseados na produção agropecuária. Richards et al. (2014) encontraram uma relação linear positiva entre a expansão da agricultura e o crescimento da população e do emprego na Amazônia.

Garret et al. (2013) destacam um feedback positivo entre a expansão da agricultura e da aglomeração dos produtores e empresas em locais ainda não desenvolvidos economicamente. No entanto, quando a produção da agricultura é orientada para os mercados globais, há mais possibilidades de que os benefícios econômicos ignorem os centros urbanos locais.

Sacchi et al. (2015) verificaram em seu trabalho que, no Chaco Seco da Argentina, a expansão da agricultura tem uma relação com o crescimento da população e do emprego nos pequenos e médios centros urbanos, gerando oportunidades de trabalho. No entanto, no longo prazo, não está claro se as novas atividades agrícolas (especialmente soja) poderão sustentar o mesmo número de postos de trabalho criados no período associado à fase de exploração inicial. Já região dos Pampas da Argentina, onde a produção de soja já está consolidada, o agronegócio promoveu o desenvolvimento econômico dos centros urbanos locais, associado à valorização das terras (Reboratti, 2010), com uma indústria emergente de máquinas e serviços agrícolas (Moltoni \& Gorenstein, 2010).

Segundo Rosa et al. (2006) e Montaldo et al. (2012), a produção de carne bovina no Brasil tornou-se uma das atividades mais importantes para o emprego e a criação de riqueza no país, apesar dos autores enfatizarem que a febre aftosa foi um fator limitante para as exportações de carne na América Latina. Apenas alguns países latinoamericanos, incluindo Chile e México, têm o status de livre da doença, sem vacinação. Na maioria deles, a doença é controlada através de uma combinação de áreas livres, sem vacinação, e áreas controladas, com vacinações.

No México, a cultura do milho tem um alto valor social e econômico, indicado pelo fato de que $30 \%$ da população empregada no setor primário estar dedicado ao cultivo deste cereal (Valdez-Vazques et al., 2010). Nesta perspectiva, a produção mexicana de milho para subsistência corresponde a $85 \%$ da produção para famílias que possuem até cinco hectares de terra. Assim, uma parte significativa da sua produção é destinada ao autoconsumo, e a outra parte da produção gera a principal fonte renda para estas famílias. Já na agricultura comercial, os vários produtos de milho são processados, como: tortilhas, farinha, amido, cereais, ração animal e outros produtos (Valdez-Vazques et al., 2010).

No Chile, Rehner et al. (2014) verificaram uma tendência para o aumento da especialização das exportações voltadas para a produção de uvas e seus derivados, bem como salmão de cativeiro, produtos fortemente ligados ao crescimento do Produto Interno Bruto (PIB) e ao crescimento das exportações. Há também evidências de uma crescente dependência da economia chilena sobre a exportação destes produtos.

No Brasil, de 2000 a 2005, a atividade canavieira gerou $14 \%$ dos empregos totais do país e apenas esta atividade reunia $6 \%$ dos empregos agroindustriais brasileiros, além de responder por 35\% do PIB e do emprego rural do Estado de São Paulo naquele período (Bragato et al., 2008). Em 2014, o Brasil empregava cerca de um milhão de pessoas, de forma direta, e aproximadamente quatro milhões, indiretamente, dos quais $95 \%$ dos trabalhadores possuíam carteira assinada, segundo a Única (2016).

\subsection{Críticas ao modelo agropecuário da América Latina}

A maioria dos indicadores sociais tem confirmado que, na última década, houve desenvolvimento socioeconômico na América Latina. Apesar de ser uma das regiões mais desiguais do mundo, as disparidades foram reduzidas substancialmente. O coeficiente de Gini, em termos de renda per capita, por exemplo, caiu sem precedentes: cinco pontos percentuais, passando de 0,57, em 2000, para 0,52, em 2012 (Vacis et al., 2015). Assim, quando analisados os números globais da região, o combate à pobreza tem sido positivo, já que o índice de Gini está diminuindo, embora a pobreza ainda tenha 
se mantido em alta. De acordo com os números da Cepalstat (s.d.), em 2014, havia 22,8\% da população da América Latina e do Caribe abaixo da linha de pobreza, sendo que $46,2 \%$ dessa população pobre se encontravam na zona rural. A magnitude da pobreza rural, por sua vez, tem variações importantes nos diferentes países. Em 2014, a pobreza no setor rural se situava em torno de $2 \%$ da população rural do Uruguai, enquanto, na Guatemala, alcançava $77,7 \%$ da população rural (CEPALSTAT, s.d.). Um estudo realizado por Vakis et al. (2015) mostrou que os pobres crônicos trabalham com frequência em setores de baixa produtividade, incluindo, segundo os autores, a agricultura. Os autores realizaram também uma análise do emprego por setores da economia, que mostrou que regiões com elevada concentração de pessoas empregadas na agricultura tendem a ter taxas mais elevadas de pobreza crônica; enquanto os setores com alta tecnologia (serviços, construção e comércio) mostraram menores taxas de pobreza crônica. Segundo aqueles mesmo autores, os empregos criados pela industrialização pagam melhor do que a agricultura. Silva et al. (2012) afirmaram que uma das variáveis que aparece como limitante para as famílias mais pobres está relacionada às condições do mercado de trabalho rural, que atuam como uma barreira para saída da pobreza rural. Por exemplo, entre 1995 e 2006, os autores acompanharam o mercado de trabalho rural da Nicarágua e verificaram que metade do mercado de trabalho rural consistia em emprego não qualificado, de baixa remuneração, o que perpetuaria o ciclo da pobreza.

Com relação ao êxodo rural e à dinâmica econômica conjuntural, Tello (2015) verificou que, nos períodos de 1980 a 2011, quase todos os países latino-americanos sofreram mudanças estruturais, diminuindo a participação nos setores da agricultura e da indústria, em favor do setor de serviços. Em alguns países, como na Argentina, houve um aumento da participação do agronegócio no PIB; ao contrário do México, na qual houve a maior taxa de industrialização entre os países latino-americanos. Porém, nos dois casos, houve aumento da distribuição de renda para aqueles países. Assim, Tello (2015) não conseguiu estabelecer relação estatística causal entre crescimento econômico geral e mudança estrutural econômica setorial, que, no caso analisado, foi a diminuição de atividade da agricultura e da indústria, em favor do aumento da atividade no setor de comércio e serviços na América Latina. Apesar de que, segundo o autor, isto pode ter ocorrido porque os indicadores oficiais não levaram em conta as atividades informais, as quais correspondem a uma parte considerável dos setores econômicos latino-americanos.

Já Awakose \& Xie (2015), ao comparar a relação do agronegócio com crescimento econômico em países em desenvolvimento da América Latina e da Ásia, verificou que, nos países latino-americanos, houve correlação positiva entre a agropecuária e desenvolvimento econômico.

É importante ressaltar que muitos fatores exógenos podem estar relacionados ao desenvolvimento econômico no setor rural. No caso de Guatemala e México, a redução da pobreza rural teve sua origem em novos padrões de migrações da população rural. Trata-se de migrações temporais, nas quais os imigrantes mantiveram um vínculo com o lugar de origem, onde está parte do grupo familiar. Neste sentido, aquelas pessoas migram para outros lugares, rurais ou urbanos, dentro de seus países ou fora deles, de onde enviam dinheiro sistematicamente. Em outras palavras, produz-se uma dissociação entre o mercado, onde se gera riqueza, e onde se realiza o consumo (Silva et al., 2012).

Há casos em que o aumento das atividades nos setores secundários e terciários, em detrimento ao setor primário, trouxe benefícios econômicos e sociais. No Peru, por exemplo, o processo de industrialização, embora tenha ocorrido relativamente lento na última década, trouxe elevação de renda per capita e de crescimento econômico. Essa industrialização, contudo, não foi capaz de diminuir a desigualdade social nos últimos anos (Maletta \& Gomes, 2015).

Um programa social, na Nicarágua, proporcionou a algumas comunidades agrícolas capacitação para seus moradores, em determinado ofício, e ofereceu subsídios para abrir negócios. Vakis et al. (2015), ao medir o impacto daquele programa, verificaram que os beneficiários que receberam o subsidio para montar um negócio tiveram uma renda $40 \%$ superior ao rendimento daqueles que mantiveram as atividades agrícolas.

Outros fatores não econômicos também afetaram o agronegócio. No caso da Colômbia, os conflitos que, desde a década de 1970, caracterizaram o País têm motivado importantes deslocamentos de populações rurais das zonas de conflito para outras áreas, o que 
tem como efeito indireto na diminuição da pobreza rural (Silva et al., 2012).

Na Nicarágua, pode ser caracterizada pela vulnerabilidade de sua economia frente aos desastres naturais, como o a Furacão Mitch (1998), e diante da variação dos preços internacionais, como ocorrera na crise do preço do café (2000). Além disso, não se tem priorizado uma política de superação da pobreza rural naquele país (Silva et al., 2012). A volatilidade de preços de algumas commodities também atrapalhou o desenvolvimento de alguns países latino-americanos, como, por exemplo, no caso da cafeicultura na Colômbia. $\mathrm{O}$ peso relativo da cafeicultura, dentro da economia nacional da Colômbia, caiu significativamente entre 2000 e 2010, e um dos motivos da diminuição da produção de café na Colômbia foi a volatilidade mundial de preço do café, diante da qual muitos produtores desistiram do negócio e migraram para a produção de palma, de frutíferas e de flores para exportação (Sanz et al., 2012). Por sua vez, mesmo com a diminuição da produção do café nos últimos anos, a produção cafeeira continua tendo grande importância para a economia colombiana, no sentido de que a atividade gerou um em cada três empregos rurais, ocupando 560 mil famílias, e permitiu que, em 2010, dois milhões de pessoas vivessem diretamente da produção de café. Infelizmente, boa parte destes empregos é sazonal e de caráter informal (Sanz et al., 2012).

Assim, a redução da pobreza na América Latina não pode estar relacionada somente ao crescimento econômico do agronegócio. Para Silva et al. (2012), há dois países onde pode-se concluir que a pobreza rural tem diminuído, ainda que não se tenha antecedentes que indiquem efeito direto da agropecuária: Guatemala e México. Os países que apresentam antecedentes mais claros dos vínculos entre o agronegócio e redução da pobreza são Brasil, Chile e Peru. No caso do Brasil, a pobreza se reduziu em todo o país, mais intensamente nas regiões Centro-Oeste e Sul. No caso do Chile, a redução também ocorreu, principalmente na zona Central, predominantemente rural. No Peru, a redução da pobreza se concentrou na região costeira, especialmente no Sul, e, em menor medida, na selva. Nos três casos, a pobreza rural persiste, com maior força, em regiões específicas nas quais o agronegócio não tem muita força. No caso do Brasil, a pobreza segue concentrada na região Nordeste; no Chile, o estudo demonstra que se manteve em níveis mais altos na região Sul; e, no
Peru, na zona da Serra (Silva et al., 2012). Dessa forma, cada país latino-americano teve uma dinâmica econômica diferenciada, devido à diversidade cultural, geopolítica, ambiental, etc., que caracterizam o desenvolvimento econômico e social da América Latina como singular e multifacetado.

\subsection{Meio ambiente}

AAmérica Latina e o Caribe possuem a maior área de floresta tropical do mundo, onde se encontra a maior biodiversidade, sendo que grande parte do estoque de carbono global está acima do solo latino-americano, além de extensas áreas protegidas por leis ambientais. Estes atributos estão ameaçados pelo desmatamento e pela expansão da agropecuária (Massia et al., 2014). Na América Central, a Guatemala e Nicarágua foram os países com maior perda de área de vegetação lenhosa. Já na América do Sul, a Argentina, o Brasil, o Paraguai e a Bolívia foram responsáveis por $80 \%$ do desmatamento em toda a América Latina, entre 2001 e 2013 (Massia et al., 2014). Estima-se que aproximadamente $52 \%$ da área de original do Cerrado foram convertidas para áreas de formação de pastagem e agricultura, representando uma ameaça a este ecossistema que possui taxas atuais de desmatamento que variam entre 22.000 e $30.000 \mathrm{~km}^{2}$ por ano (Santos et al., 2014). A expansão do cultivo da soja na região latino-americana tem levantando preocupações sobre a sua própria sustentabilidade, ou seja, o seu impacto a longo prazo sobre os recursos naturais, em especial as áreas de floresta. O desmatamento tem avançado em algumas áreas da Argentina, Brasil e Paraguai, o que poderia estar influenciando negativamente, acarretando mudanças climáticas na região sul da América. Segundo OConnor (2013), o fenômeno da seca causado pelo El Nino pode estar relacionado com o desmatamento, porém, segundo o autor, ainda não cientificamente comprovado.

Com relação às queimadas, muitas vezes o fogo tem sido o principal meio utilizado para abrir novas áreas agrícolas na América Latina. O acúmulo de biomassa causada pelas vegetações nativas pode ocasionar incêndios com altas temperaturas, que são prejudiciais à fauna e à flora, além de expor o solo aos processos erosivos e de lixiviação. Além disso, a fumaça das queimadas contém gases que contribuem para o efeito estufa, trazendo prejuízos econômicos e para a saúde da sociedade (Cochrane, 2009). 
A ampliação das áreas cultivadas pode ser discutida também em relação a outros recursos escassos, como a água, especialmente nas regiões semiáridas. No Chile, por exemplo, tem ocorrido conflitos relacionados com a escassez de água, devido a este recurso ser um fator chave exigido tanto no setor da mineração, como nos setores agrícolas (Romero et al., 2012; Rehner et al., 2014). Corroborando esta questão da água no Chile, segundo Almeida (2014) existem leis chilenas que reservam áreas específicas destinadas para aquicultores, com o intuito de evitar possíveis conflitos de uso dos recursos naturais comuns às organizações de pescadores e também para a gestão dos estoques naturais. Dessa forma, as leis contribuem para o ordenamento pesqueiro e, consequentemente, para o desenvolvimento das atividades aquícolas.

\subsection{Segurança alimentar}

A segurança alimentar e nutricional, segundo a Organização das Nações Unidas para a Alimentação e a Agricultura (FAO), consiste na realização do direito de todos ao acesso regular e permanente a alimentos de qualidade, em quantidade suficiente, sem comprometer o acesso a outras necessidades essenciais, tendo como base práticas alimentares promotoras de saúde, que respeitem a diversidade cultural e, ainda, que sejam ambiental, cultural, econômica e socialmente sustentáveis (Pinheiro, 2011).

A Via Campesina, articulação mundial de camponeses dos quatro continentes (Ásia, América, África e Europa), questiona o conceito de segurança alimentar difundido pela FAO, alegando que ele se adequa apenas as políticas neoliberais do novo agronegócio. A crítica da Via Campesina se baseia na hipótese de que as políticas de segurança alimentar só se preocupam em garantir alimentos, sem se importar com a origem desses alimentos e com a maneira como eles são produzidos, o que contribuiria para inviabilizar a agricultura camponesa, uma vez que a mera oferta de alimentos pode ser atendida através da importação ou da produção em larga escala de alguns produtos em forma de monocultura (Campos \& Campos, 2007). Assim, para a Via Campesina, os camponeses deveriam ser privilegiados com políticas de incentivo à produção de alimentos, o que garantiria a segurança alimentar das famílias produtoras e da sociedade local.

Do outro lado, Colborn (2009), critica este modelo em que camponeses não deveriam ser encorajados a deixar os campos, mas a agarrar-se a terra, para produzir mais alimentos e assim, proteger os seus irmãos urbanos do mercado internacional implacável. Para o autor, os camponeses são muitas vezes vistos como os guardiões da cultura nacional, um bastião de defesa contra a "globalização". Então é ainda mais tentador sugerir que eles fiquem estagnados, vivendo muitas vezes de uma forma deplorável, situação que, na prática, os próprios idealistas do campesinato não se submetem.

O fato é que há uma tendência de aumento da demanda mundial de alimentos e biocombustíveis, juntamente com o aumento do fornecimento latinoamericano para os próximos anos. Segundo OConnor (2013) há uma grande volatilidade nos preços das commodities, especialmente de produtos alimentares, e, se esta tendência continuar, a questão da segurança alimentar na América Latina terá de enfrentar preços mais altos para os próximos anos. Uma visão otimista, sugerida por OConnor (2013) e adaptada para este trabalho, enfatiza-se nas oportunidades de exportação para os mercados emergentes, já que com o avanço do desenvolvimento econômico e com o aumento da população, todos os países emergentes exigirão mais comida. Assim, alguns aspectos de modelos de crescimento endógeno poderão levar ao equilíbrio econômico global, como a mudança tecnológica e o impacto das instituições sobre o desenvolvimento social. Se isso ocorrer desta forma, os países latino-americanos poderiam ser influenciados positivamente.

Uma visão mais conservadora, também adaptada à visão de OConnor (2013), afirma que, com a crise europeia (Grécia, Espanha e Itália) agravada pelas questões dos refugiados do Oriente Médio, a economia europeia poderá entrar em depressão, diminuindo suas importações, de modo que as exportações da China podem cair. Assim, com a economia chinesa diminuindo, haveria diminuição dos preços oferecidos pelo mercado latino-americano, o que acarretaria um cenário difícil para economias da América do Sul.

\section{CONSIDERAÇÕES FINAIS}

Na presente pesquisa foi possível verificar que houve efetivamente um dinamismo da produção agropecuária, o qual, de acordo ao modelo de desenvolvimento vigente, está concentrado nas regiões em que cada país conta com suas vantagens naturais para produção, e, em outros casos, criou-se vantagens comparativas, sempre orientadas para o mercado externo. 
Observou-se também uma influência positiva do agronegócio na geração de renda e na qualidade de vida da população na maioria dos países latinoamericanos, enquanto, em outros países, não foi possível estabelecer uma correlação entre agropecuária e desenvolvimento econômico-social.

A questão fundamental para que ocorra o bemestar social é o gerenciamento da riqueza produzida pelo crescimento do agronegócio, aplicado em políticas públicas, no sentido da diminuição das desigualdades sociais. Assim, o Estado ainda tem um grande papel, como regulador do seu próprio desenvolvimento regional. Um grande exemplo disso na América Latina é a Costa Rica. O país, segundo Colburn (2009) é um grande importador de alimentos e, ainda assim, tem uma economia equilibrada, ganhando receitas provenientes do turismo, das exportações tradicionais, como café e bananas, e de uma variedade de exportações não tradicionais, desde peixe seco a softwares.

Outras questões como segurança alimentar, expansão da produção das commodities tradicionais, efeitos climáticos, devem ser discutidas amplamente com a sociedade, com suporte em resultados empíricos, evitando assim a subjetividade, mas sempre respeitando a maneira filosófica de cada ponto de vista, já que o que está em evidência é atingir o bem-estar social, que, por sua vez, tem caráter mais amplo.

O agronegócio também não pode ser sempre acusado de um antagonista ao meio ambiente, já que existem leis de proteção ambiental em todos os países latinoamericanos. Deve-se, então, exigir primeiramente dos responsáveis e dirigentes o fomento à educação ambiental, sendo que todos os excessos devem ser combatidos com uma fiscalização forte, que, infelizmente, ainda é deficitária na América Latina como um todo.

É importante ressaltar a importância dos sistemas produtivos agrícolas na América Latina, por se tratar de uma vantagem comparativa para a promoção do desenvolvimento de toda cadeia agropecuária.

\section{REFERÊNCIAS BIBLIOGRÁFICAS}

ALMEIDA, A.; RODRIGUES, R.L.; FREITAS, R.R. Potencialidades de investimento aquícolas no estado do espírito santo: uma breve caracterização do setor. ACTAPESCA-Acta fisheries and aquaculture/Acta Pesca e Aquicultura, v.2, n.1, 2014.
AMÉRICA, O.L. The economic development of Latin America and its principal problems, 1950.

AOKI, Masahiko. Historical sources of institutional trajectories in economic development: China, Japan and Korea compared. Socio-

Economic Review, v.11, n.2, p.233-263, 2013.

AWOKUSE, Titus O.; XIE, R. Does agriculture really matter for economic growth in developing countries? Canadian Journal of Agricultural Economics/Revue canadienne d'agroeconomie, v.63, n.1, p.77-99, 2015.

BELEÑO, C.A.M. About challenges of the modern world: Health, environment and social development América Latina case. Economic and Social Development: Book of Proceedings, p. 199, 2014.

BEGHIN, J.C. NAFTA: Implications for Mexican and Midwestern Agriculture. Iowa Ag Review, v.7, n.1, p.4, 2015.

BHAGWATI, J.; SRINIVASAN. T.N. Foreign trade regimes and economic development: India. New York: Columbia University Press, 1975.

BRAGATO, I.R.; SIQUEIRA, E.S.; GRAZIANO, G.O.; SPERS, E.E. Produção de açúcar e álcool vs. responsabilidade social corporativa: as ações desenvolvidas pelas usinas de cana-de-açúcar frente às externalidades negativas. Gestão e Produção, v.15, n.1, p.89-100, 2008.

BRESSER-PEREIRA, L.C. Do antigo ao novo desenvolvimentismo na América

Latina. D'AGUIAR, R.F. (Ed.).

Desenvolvimento econômico e crise. Rio de Janeiro: Contraponto Editora, p.37-65, 2012.

CAMPOS, R.S.; CAMPOS, C.S.S. Soberania alimentar como alternativa ao agronegócio no Brasil. Scripta Nova: Revista Electrónica de Geografía y Ciencias Sociales, n.11, p.66, 2007.

CEPAlstat. Comissión Económica para América Latina y el Caribe. [s.d.]. Disponível em: <http://estadisticas.cepal.org/ cepalstat/WEB_CEPALSTAT/Portada.asp/> Acessado em: 05 de maio de 2016 . 
CASTILLO-VERGARA, Mauricio. Implementation of a cleaner production agreement and impact analysis in the grape brandy (pisco) industry in Chile. Journal of Cleaner Production, 2013.

CHENERY, H.B.; ECKSTEIN, P. Development Alternatives for Latin América. Journal of Political Economy, v.78, n.4, p.966-1006, 1970.

COCHRAne, M.A. Tropical Fire Ecology: Climate change, Land use and Ecosystem Dynamics. Ed. Praxis Plublishing Ltd, Chichester, UK, 2009.

COLBURN, F. Latin América: Captive to Commodities. 2009. Dissertação. University of Pennsylvania. Disponível em: <w3 http://muse.jhu.edu/article/ 256419>. Acesso em: 14 mai. 2016.

DA SILVA, L.G. A expansão da pecuária na Amazônia. Revista de Estudos Sociais, v.15, n.29, p.79-96, 2014.

DINIZ, E. Neoliberalismo e corporativismo: as duas faces do capitalismo industrial no Brasil. Revista Brasileira de Ciências Sociais, v.7, n.20, p.31-46, 1992.

FAOSTAT. Food and Agriculture Organization of the United Nations - Statistics Division. [s.d.]. Disponível em: <http:// faostat3.fao.org/home/index.html/> Acessado em: 01 de novembro de 2015.

GARRETT, R.D.; LAMBIN, E.F.; NAYLOR, R.L.

The new economic geography of land use change: Supply chain configurations and land use in the Brazilian Amazon. Land Use Policy, n. 34, p.265-275, 2013.

GOLLIN, D.; PARENTE S. L.; ROGERSON, R. The role of agriculture in development. Américan Economic Review, v.92, n.2, p.160-64, 2002.

GREGORIO, J. Economic growth in Latin América. Journal of development economics, v.39, n.1, p.59-84, 1992.

GUEDES, S.N.R.; VIAN, C.E.F.; DE MORAES, G.I.; MAIANTE, M. Uma caracterização das transformações econômicas e sociais na agroindústria canavieira da Argentina, Brasil e México. História Unisinos, v.17, n.3, p.280-292, 2013.
HUACUJA, F.E. Agricultural policy and the feed industry in Mexico. Mexican Studies/ Estudios Mexicanos, v.29, n.1, p.61-84, 2013.

KRAPOVICKAS, J. Socioenvironmental change in the Argentinean Chaco and its relation with soybean expansion in the 90s. 2009. Tese de Doutorado. Universidad Autónoma de Barcelona, Barcelona.

LANDINI, F. Problemas de la extensión rural en América Latina. Revista Perfiles

LatinoAméricanos, v.24, n.47, p.47-68, 2016.

LORENZO, C.; YAMIN VAZQUEZ, P. The rise of biofuels in IR: the case of Brazilian foreign policy towards the EU. Third World Quarterly, p.1-15, 2016.

MALETTA, H.; GÓMEZ, R. Agricultura, alimentación y comercio exterior en el Perú: el problema de la autosuficiencia. Apuntes: Revista de Ciencias Sociales, n.14, p.39$78,2015$.

MARTINEZHYPHENVAZQUEZ, J.; VULOVIC, V. Estructura impositiva en América Latina: efectos sobre la economía real. Revista de Economía Mundial, v.37, 2014.

MASCIA, M.B.; PAILLER, S.; KRITHIVASAN, R.; ROSHCHANKA, V.; BURNS, D.; MLOTHA, M.J.; PENG, N. Protected area downgrading, downsizing, and degazettement (PADDD) in Africa, Asia, and Latin América and the Caribbean, 1900-2010. Biological

Conservation, n.169, p.355-361, 2014.

MASSARDIER, G.; SABOURIN, E.

Internationalization and dissemination of rural territorial development public policies: model hypotheses for Latin

América. Sustentabilidade em Debate, v.4, n.2, p.83-100, 2013.

MONTALDO, H.; CASAS, E.; STERMAN FERRAZ, J.B.; VEGA-MURILLO, V.E.; ROMÁNPONCE, S.I. Opportunities and challenges from the use of genomic selection for beef cattle breeding in Latin América, 2012. 
MOLTONI, L.; GORENSTEIN, S. Territorios de la industria de Maquinaria Agrícola Argentina. Conocimiento, aprendizaje y redes locales de cooperación. In: XI International Seminar of the Latin Américan Research Network on Globalization and Territory, Universidad Nacional de Cuyo, Mendoza, Argentina, 2010.

O'CONNOR, E. China, Brazil and Argentina: Agricultural Trade and Development. Américan Journal of Chinese Studies, v.20, n.2, 2013.

PERROTTI, D.E. The People's Republic of China and Latin América: the impact of Chinese economic growth on Latin American exports. CEPAL Review, n.116, p.47-60, 2015.

PINHEIRO, A. Análise histórica do processo de formulação da Política Nacional de Segurança Alimentar e Nutricional (2003-2006): atores, idéias, interesses e instituições na construção de consenso político. 2011. 234p. Tese de Doutorado. Universidade de Brasília, Brasília.

PREBISCH, R. O desenvolvimento econômico da América Latina e seus principais problemas. Revista Brasileira de Economia, v.3, n.3, p.47-111, 1949.

REHNER, J.; BAEZA, S.A.; BARTON, J.R. Chile's resource-based export boom and its outcomes: Regional specialization, export stability and economic growth. Geoforum, v.56, p.35-45, 2014.

RICHARDS, P.; PELLEGRINA, H.; VANWEY, L.; SPERA, S. Soybean development: The impact of a decade of agricultural change on urban and economic growth in Mato Grosso, Brazil. PloS One, v.10, n.4, 2014.

ROCHA DE SOUSA, M. A Global Governance Approach to FAO: Proximity, Legitimacy \& Accountability-Averting the global food crisis. 2013.

ROSA, F.RT.; ALENCAR, L.; JUNIOR, A.M.T. Mudanças na exportação de carnes. Agroanalysis, v.26, n.2, p.15-17, 2006.
REBORATTI, C. Un mar de soja: La nueva agricultura en Argentina y sus consecuencias. Revista de Geografía Norte Grande, n. 45 , p.63-76, 2010.

SVAMPA, M. Consenso de los Commodities y lenguajes de valoración en América

Latina. Nueva Sociedad, v.244, p.30-46, 2013.

SACCHI, L.V.; GASPARRI, N.I. Impacts of the deforestation driven by agribusiness on urban population and economic activity in the Dry Chaco of Argentina. Journal of Land Use Science, p.1-17, 2015.

SANTOS, P.R.; PEREIRA, G.; ROCHA, L.C. Spatial distribution analysis of fire sources for the Cerrado biome (2002-2012). Caderno de Geografia, v.24, n.1, p.133-142, 2014.

SANZ, C.G.C.; MEJÍA, C.V.; GARCÍA, E.C.; TORRES, J.S.A.; CALDERÓN, E.Y.T. El mercado mundial del café y su impacto en Colombia. Banco de la República, N.9612, 2012.

SCHUlTZ, T.W. Transforming traditional agriculture. New Haven: Yale University Press, 1964.

SILVA, J.G.; GÓMEZ, S.; CASTAÑEDA, R. "Boom" agrícola e persistência da pobreza na américa latina: algumas reflexões. Revista Nera, n.16, p.7-21, 2012.

SPRAOS, J. The statistical debate on the net barter terms of trade between primary commodities and manufactures. The Economic Journal, v.90, n.357, p.107-128, 1980.

STALLINGS, B.; PERES NÚÑEZ,

W. Crescimento, emprego e equiidade: o impacto das reformas econômicas na América Latina e Caribe. Campus, 2002.

STEIN, S.J.; STEIN, B.H. The colonial heritage of Latin América: essays on economic dependence in perspective. New York: Oxford University Press, 1970.

TELLO, M.D. Desigualdad, crecimiento económico y cambio estructural: Relaciones teóricas y evidencia de los países de América Latina. PUCP, n.402, 2015. 
TEUBAL, M. O campesinato frente à expansão dos agronegócios na América Latina. PAULINO, E.T.; FABRINI, J.E. (organizadores).

Campesinato e territórios em disputa. São Paulo: Expressão Popular, UNESP, Programa de Pós-Graduação em Geografia, p. 139-160, 2008.

UNICA. União da indústria de cana de açúcar. 2016. Disponível em: <http://www.unica.com.br/> Acessado em: 14 de maio de 2016.

VALDEZ-VAZQUEZ, I.; ACEVEDO-BENÍTEZ, J.A.; HERNÁNDEZ-SANTIAGO, C. Distribution and potential of bioenergy resources from agricultural activities in Mexico. Renewable and Sustainable Energy Reviews, v.14, n.7, p.2147-2153, 2010.
VAKIS, R.; RIGOLINI, J.; LUCCHETTI, L. Los olvidados: pobreza cronica en América Latina y el Caribe-resumen ejecutivo. 2015. Disponível em: < http://agris.fao.org/agris search/ search.do? record I D = US $2015601183>$ Acessado em: 01 de maio de 2016 .

WILKINSON, J. A agricultura familiar ante o novo padrão de competitividade do sistema agroalimentar na América Latina. Estudos Sociedade e Agricultura, v.1, 2013.

Recebido para publicação em 11/2/2017 e aprovado em 28/3/2017. 